\title{
Impact of Wildfire Smoke Events on Indoor Air Quality and Evaluation of a Low-cost Filtration Method
}

\author{
Nathaniel W. May ${ }^{1 *}$, Clara Dixon ${ }^{1}$, Daniel A. Jaffe ${ }^{1,2}$ \\ ${ }^{1}$ University of Washington Bothell, Bothell, WA 98011, USA \\ ${ }^{2}$ University of Washington, Seattle, WA 98195, USA
}

\begin{abstract}
Increased wildland fire activity is producing extreme fine particulate matter ( $\left.P M_{2.5}\right)$ concentrations impacting millions of people every year, especially in the western United States (US). Recommendations for limiting exposure to $\mathrm{PM}_{2.5}$ and associated adverse health outcomes focus on staying inside, closing windows and doors, and increasing filtration; however, relatively little is known about indoor air quality (IAQ) during major smoke events. Indoor and outdoor hourly $\mathrm{PM}_{2.5}\left(\mu \mathrm{g} \mathrm{m}^{-3}\right.$ ) measurements from the publicly available PurpleAir sensor (PAS) network were analyzed for 42 sites ( 26 residential, 6 school, 10 commercial) across the western US during a September 2020 period of heavy wildfire smoke influence. The fraction of ambient $\mathrm{PM}_{2.5}$ that penetrates indoors and remains airborne $\left(F_{i n}\right)$, as well as the ratio $(I / O)$ and correlation coefficient $\left(\mathrm{R}^{2}\right)$ of indoor to outdoor $\mathrm{PM}_{2.5}$ concentrations, were lower in residential compared to commercial and school buildings. Interventions to improve IAQ were highly influential in $\mathrm{PM}_{2.5}$ infiltration in residential case studies, with multiple, continuously run filter units associated with lower $F_{\text {in, }} 1 / 0$, and $\mathrm{R}^{2}$. A low-cost $\mathrm{PM}_{2.5}$ filtration method consisting of a Minimum Efficiency Rating Value-13 (MERV-13) filter attached to a box fan is evaluated as an alternative for improving IAQ during wildland fire smoke events. The MERV-13 fan filter unit proved highly effective at reducing indoor $\mathrm{PM}_{2.5}$ and particles 0.3-1.0 $\mu \mathrm{m}$ measured by PAS and a particle counter, respectively, when recirculating air in a single room. Low-cost filtration methods can have significant benefit for filtering submicron smoke particles and may reduce exposure to $\mathrm{PM}_{2.5}$ during wildfire smoke events.
\end{abstract}

Keywords: $\mathrm{PM}_{2.5}$, Indoor air pollution, Filtration, Biomass burning, Laser particle counter

Received: March 3, 2021

Revised: April 30, 2021

Accepted: May 9, 2021

${ }^{*}$ Corresponding Author:

natemay@uw.edu

Publisher:

Taiwan Association for Aerosol Research

ISSN: $1680-8584$ print

ISSN: 2071-1409 online

cc) Copyright: The Author(s). This is an open access article distributed under the terms of the Creative Commons Attribution License (CC BY 4.0), which permits unrestricted use, distribution, and reproduction in any medium, provided the original author and source are cited.

\section{INTRODUCTION}

The area burned by wildland fires in the United States (US) increased substantially over the past two decades (Jaffe et al., 2020), exceeding 3 million hectares burned in 6 of the past 10 years (National Interagency Fire Center, 2020). This is part of a larger US trend of increasing frequency and area burned, as well as fire season length, since the 1980s (Abatzoglou and Williams, 2016; Westerling, 2016). Health impacts from exposure to smoke include cardiovascular and respiratory mortality and morbidity, adverse reproductive, developmental, and neurodegenerative diseases, as well as eye irritation, wheezing, and coughing (Reid et al., 2016; Thurston et al., 2017; Cascio, 2018). High risk populations include those with respiratory and cardiovascular disease, pregnant women and their fetuses, young children, and older adults (Rappold et al., 2017; Hooper and Kaufman, 2018). Fires in 2017 and 2018 led to the highest observed fine particulate matter $\left(\mathrm{PM}_{2.5}\right)$ concentrations ever observed at regulatory monitors in the US at the time, with 24-hour averaged values over $600 \mu \mathrm{g} \mathrm{m}^{-3}$ in some locations (Laing and Jaffe, 2019). However, summer 2020 fires shattered those records. In high fire years, extreme $\mathrm{PM}_{2.5}$ concentrations impact millions of people, especially in the western US. Recommendations for limiting exposure to $\mathrm{PM}_{2.5}$ and other pollutants during wildfire smoke events focus on staying indoors, reducing infiltration, and 
increasing filtration (Laumbach, 2019; Davison et al., 2021).

Infiltration of $\mathrm{PM}_{2.5}$ occurs through unintentional cracks in the building envelope, open windows or doors, and HVAC systems with outdoor intakes. The fraction of ambient $\mathrm{PM}_{2.5}$ that penetrates indoors and remains airborne $\left(F_{i n}\right)$, as well as indoor source contributions $\left(C_{s}\right)$, can be assessed from $\mathrm{PM}_{2.5}$ concentrations indoors $\left(C_{i}\right)$ and outdoors $\left(C_{0}\right)$ with the following equation:

$C_{i}=F_{i n} C_{o}+C_{s}$

Barn et al. (2008) examined $F_{\text {in }}$ with and without high-efficiency particulate air (HEPA) filtration in 21 British Columbia homes, with values during summer wildfires ranging from 0.19 with filtration to 0.61 without. Kirk et al. (2018) examined two homes in the Pacific Northwest during a high fire occurrence summer and observed good correlations between indoor (I) and outdoor (O) $\mathrm{PM}_{2.5}$ concentrations but relatively low $\mathrm{I} / \mathrm{O}$ ratios $(0.10-0.26)$. $F_{\text {in }}$ and $\mathrm{I} / \mathrm{O}$ ratios during smoke events are influenced by road proximity, building envelope, occupant behaviors, and indoor PM 2.5 sources (Reisen et al., 2019; Shrestha et al., 2019).

Some in the air quality community have suggested that low-cost methods using Minimum Efficiency Reporting Value-13 (MERV-13) filters could reduce indoor smoke (https://pscleanair.go v/525/DIY-Air-Filter). It is not clear how well low-cost filtration methods will remove ultrafine aerosol particles in smoke (Laing et al., 2016) because the MERV-13 rating only requires a filter remove at least $50 \%$ of particles in the $0.3-1.0 \mu \mathrm{m}$ size range (https://www.nafahq.org/understa nding-merv-nafa-users-guide-to-ansi-ashrae-52-2/). However, a low-cost MERV-13 fan filter unit (FFU) achieved a $>75 \%$ reduction in residential and school $\mathrm{PM}_{1}$ particle mass concentrations indoors relative to ambient smoke haze concentrations (Tham et al., 2018, 2020). The health/economic benefits of filtration interventions are likely to exceed purchase and operation costs, particularly if targeted to vulnerable populations (Fisk and Chan, 2017; Allen and Barn, 2020).

PurpleAir sensors (PAS) detect $\mathrm{PM}_{2.5}$ using the Plantower PMS5003 laser scattering sensor. Several studies have found these to be precise, but not accurate (Ardon-Dryer et al., 2020; Li et al., 2020). For accurate measurements, calibration by a $\mathrm{PM}_{2.5}$ reference is required. PAS are now widely used, with data available in real-time (https://www2.purpleair.com/). Recently, the US EPA developed a single correction equation for PAS and incorporated ambient outdoor data into its real-time AirNow smoke website (https://www.airnow.gov/fires/). In addition, increased availability of indoor PAS measurements presents the opportunity to significantly improve our understanding of indoor air quality (IAQ). For this study our goals are:

1. Evaluate the infiltration of smoke in different building types and the impact of interventions to improve IAQ using available data from the PurpleAir sensor network.

2. Evaluate a low-cost $\mathrm{PM}_{2.5}$ filtration method that might be able to significantly improve IAQ during smoke events.

The results presented herein are highly relevant to millions of people impacted by wildland fire smoke each year and motivate further study on the impacts of smoke infiltration on IAQ and associated adverse health impacts. The dissemination of methods that the general public can easily adopt to reduce $\mathrm{PM}_{2.5}$ exposure is of critical need in response to increasingly common wildland fires.

\section{EXPERIMENTAL}

First, we examine the relationship between indoor and outdoor $\mathrm{PM}_{2.5}$ concentrations during a major smoke event. Hourly $\mathrm{PM}_{2.5}\left(\mu \mathrm{g} \mathrm{m}^{-3}\right.$ ) measurements were obtained from the publicly available PAS network for 42 sites across the western US during a period of heavy wildfire smoke influence from September 5-15, 2020. The 42 sites used are a mix of 26 "residential", 6 "school", and 10 "commercial" buildings. Sites were categorized by a combination of publicly listed PAS name and location characteristics on Google Maps (maps.google.com). Locations were selected from existing PAS network voluntary participants and may not represent the general population. Building occupancy, indoor air quality interventions, opening of windows and doors and confirmation of building classification and location were provided by PAS users who responded to a request for information. Selected responding locations, which included five residential, one school, and two 
commercial buildings, served as case studies. In comparison to previous surveys of wildfire impacts on IAQ (Barn et al., 2008; Kirk et al., 2018; Reisen et al., 2019; Barkjohn et al., 2021), we examine a larger sample and more building types, but with less information on building characteristics and occupant behavior, and no examination of chemical composition of pollutants.

PAS data, designated by the user as outdoors or indoors, were downloaded as hourly averages from the PurpleAir website (www2. purpleair.com). Data were corrected with the EPA national correction equation (http:/fire.airnow.gov), which was developed by comparing sensor data across the US to measurements by federal reference and equivalent methods (Barkjohn et al., 2020):

Corrected $\mathrm{PM}_{2.5}=($ raw PAS data $\times 0.52)-(\mathrm{RH} \times 0.085)+5.71$

The slope of the EPA national correction equation is within $3 \%$ of the slope of a smoke specific PAS correction equation based on multiple types of fires in the US (Holder et al., 2020) and within the range of PAS smoke adjustment factors (0.44-0.53), linear adjustments with zero intercepts, for wildfires in California and Utah (Delp and Singer, 2020). We focused on the strong wildfire episodes that occurred in the western US during the period of September 5-15, 2020. We identified smoke events and paired PAS sensors (one indoors and one outdoors) as follows:

A: Outdoor PAS corrected $\mathrm{PM}_{2.5}$ values exceeded $80 \mu \mathrm{g} \mathrm{m}^{-3}$ for 12 hours and smoke was identified using the NOAA HMS product.

B: PAS outdoor and indoor sensors were located within $0.5 \mathrm{~km}$ of each other.

Infiltration factor $\left(F_{\text {in }}\right)$, and concentration of particles from indoor sources $\left(C_{S}\right)$, as well as correlation coefficients $\left(R^{2}\right)$, were calculated from a linear regression of indoor and outdoor PAS $\mathrm{PM}_{2.5}$ concentrations (Eq. (1)). The ratio of indoor to outdoor $\mathrm{PM}_{2.5}(\mathrm{I} / \mathrm{O})$ was calculated from respective means. Individual PAS locations are detailed in Table S1.

Next, we evaluate the utility of a low-cost filtration method. This method consisted of a $20^{\prime \prime} \times$ 20 " MERV-13 air filter, attached to a standard home box fan with tape. Photographs of the MERV-13 FFU, which can be assembled at home for $\sim 30-50 \$$, are shown in Fig. S1. Average air speed, measured with a VT140 Thermo-Anemometer directly in front of the fan outflow, was multiplied by filter area to estimate an air supply rate $\left(Q_{p}\right)$ of $730 \mathrm{CFM}$, which was comparable to the FFU presented in Tham et al. (2018) ( $Q_{p}=735$ CFM). Attaching the MERV-13 filter closely to the box fan did not create excess heat over 8 hours of operation. However, airflow resistance by the filter contributed to a $33 \%$ reduction in airflow.

PAS measurements were obtained from two rooms in a single-family residence in Seattle, WA, which served as a case study for the evaluation of the low-cost filtration method presented here. Room A was $200 \mathrm{~m}^{3}$, with multiple windows and large openings to the interior and two exterior doors, and Room B was $50 \mathrm{~m}^{3}$, with only one window, one interior door, and one exterior door. First, identical MERV-13 FFUs simultaneously recirculated air in two separate rooms, both unoccupied with all doors and windows closed to reduce natural ventilation, in a Seattle, WA, home on September 13, 2020. We used a mass balance approach (Shi and Li, 2019) to estimate the infiltration rate $\left(Q_{i n f}\right)$ of each room from the clean air delivery rate (CADR) of the FFU and simultaneously measured post-filtration steady state $\mathrm{PM}_{2.5} \mathrm{I} / \mathrm{O}$ ratios based on the following equation:

$Q_{\text {inf }}=\frac{I / O \times(C A D R+K \times \text { Room Volume })}{P-I / O}$

Penetration $(P)$ was set to 1 and indoor deposition rate $(K)$ was set to $0.39 \mathrm{~h}^{-1}$ (Thatcher and Layton, 1995; Wallace, 1996). To further evaluate submicron particle removal efficiency by the MERV-13 FFU, a Grainger 23V750 handheld particle counter (Reiman et al., 2018) was used to measure size-resolved particle number concentrations alongside PAS measurements during an additional test of the FFU in Room B on September 14, 2020. A Grimm Environmental Dust Monitor (EDM-180) (Grimm and Eatough, 2009) was later used to calculate a correction equation for the Grainger number concentrations (Fig. S2). Details of size-resolved particle measurements are presented in the Supporting Information. 


\section{RESULTS AND DISCUSSION}

\subsection{Indoor and Outdoor $\mathrm{PM}_{2.5}$ Relationship in Buildings in the Western United States}

Corrected (Eq. (2)) hourly average concentrations of indoor and outdoor $\mathrm{PM}_{2.5}$ measured by PAS, at 42 western US locations were used to evaluate $\mathrm{PM}_{2.5}$ infiltration by building type. Box plots of $F_{i n}, C_{S}, \mathrm{R}^{2}$, and $\mathrm{I} / \mathrm{O}$ by building type are presented in Fig. 1. More complete information on these 42 buildings is given in Table S1. The large range of $F_{\text {in }}(0.01-0.87)$ observed in residential buildings $(\mathrm{N}=26)$ is consistent with previous observations of residential $F_{\text {in }}(0.01-1.10)$ during wildfire smoke periods (Barn et al., 2008). The low median $F_{\text {in }}(0.21)$ in residential buildings was more similar to median $F_{\text {in }}$ of summer homes with HEPA filtration (0.19) than without (0.61) (Barn et al., 2008). Commercial buildings $(N=10)$ exhibited a higher median $F_{\text {in }}(0.45)$, with a smaller range of $0.30-0.71$, and school buildings $(\mathrm{N}=6)$ had the highest median $F_{\text {in }}$ value $(0.68)$, with a wide range of 0.41-0.80. $F_{\text {in }}$ thus reflects ASHRAE Standards 62.1 and 62.2 recommended outdoor air ventilation rates, which are lowest for residential buildings (ASHRAE, 2019a) and increase
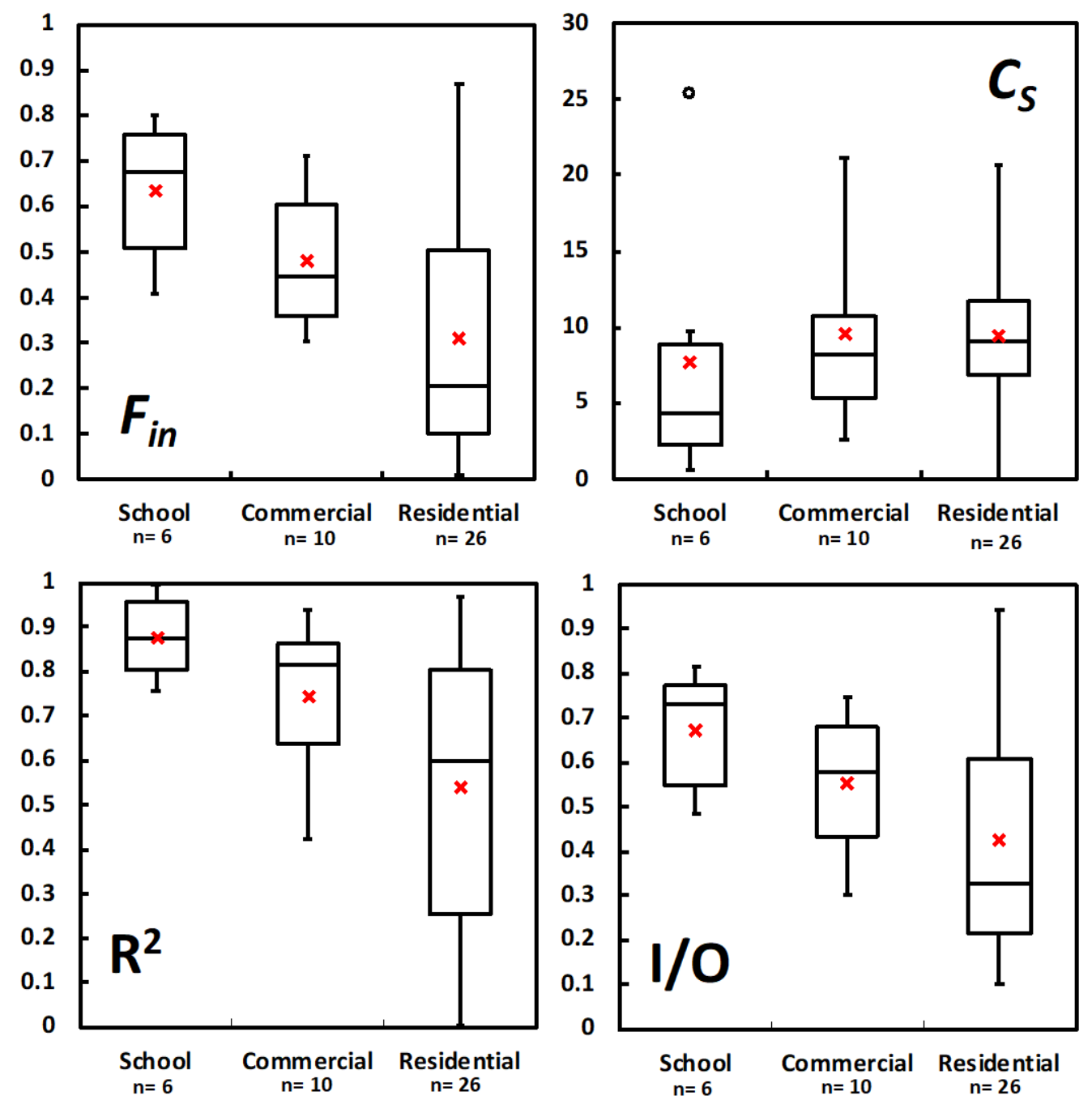

Fig. 1. Box plots by building type of infiltration factor $\left(F_{i n}\right)$ and concentration of particles from indoor source $\left(C_{S}\right)$, as well as indoor to outdoor $\mathrm{PM}_{2.5}$ mass concentration correlation coefficients $\left(\mathrm{R}^{2}\right)$ and ratios (I/O), for the $6 \mathrm{school}, 10 \mathrm{commercial}$, and 26 residential PurpleAir sensor locations during a September 5-15, 2020, wildfire smoke-impacted period. Lower and upper box boundaries are $25^{\text {th }}$ and $75^{\text {th }}$ percentiles, respectively, lower and upper error lines are $10^{\text {th }}$ and $90^{\text {th }}$ percentiles, respectively, lines inside box are medians, red Xs are means, and circles are outlier data. 
from commercial to school buildings (ASHRAE, 2019b). However, the conclusions of this survey are limited without coinciding records of occupant activity and measurements of air exchange rate (AER), which is controlled by leakage, mechanical and natural ventilation. For example, school and commercial $F_{\text {in }}$ values in this study may have been further elevated by measures to increase outdoor air exchange in shared buildings during the COVID-19 pandemic (Schoen, 2020). Substantial reductions in occupancy in commercial and school buildings due to pandemic restrictions could also have influenced $F_{\text {in }}$.

I/O ratios were below 1 and mirrored the building dependency of $F_{\text {in }}$ values, with medians increasing from residential (0.33), to commercial (0.58), to schools (0.73). Median $C_{S}$ were slightly higher in residential $\left(6.29 \mu \mathrm{g} \mathrm{m}^{-3}\right)$ than commercial $\left(5.38 \mu \mathrm{g} \mathrm{m}^{-3}\right)$ and school $\left(1.55 \mu \mathrm{g} \mathrm{m}^{-3}\right)$ buildings. The percentage of $\mathrm{PM}_{2.5}$ indoors due to infiltration can be described by the correlation coefficient $\left(R^{2}\right)$ of indoor and outdoor $\mathrm{PM}_{2.5}$ (Bucur and Danet, 2019). Residential specific indoor sources (i.e., cooking, cleaning) (Wallace, 2006) may have contributed to lower residential $R^{2}$ (median = 0.77 ), while the elevated $R^{2}$ observed in high AER commercial (median $=0.90$ ) and school (median $=0.93$ ) buildings demonstrates that infiltration by ventilation was the predominant source of $\mathrm{PM}_{2.5}$ therein. Increased filtration can also lower $\mathrm{R}^{2}$ (Deng et al., 2015), as well as $F_{\text {in }}$ and I/O (Barn et al., 2008; Allen et al., 2011; Wheeler et al., 2014; Ward et al., 2017). Therefore, the differences observed in wildfire smoke $\mathrm{PM}_{2.5}$ infiltration (Fig. 1) must be examined in relation to both ventilation and filtration.

\subsection{Impact of Indoor Air Quality Interventions: Residential Case Studies}

Time series of indoor and outdoor $\mathrm{PM}_{2.5}$, as well as linear regression plot of indoor and outdoor $\mathrm{PM}_{2.5}$ used to calculate $F_{\text {in }}$ and $C_{S}$, for three residences in the western US (WA, NV, ID) is presented in Fig. 2. The NV residence $\left(F_{i n}=0.04\right)$ reported the continuous use of 3 HEPA filters and the WA residence $\left(F_{\text {in }}=0.09\right.$ ) reported the continuous use of 4 HEPA filters, with both reporting keeping all windows and doors closed to reduce natural ventilation. The ID residence reported using a furnace fan with a MERV-12, which ran 4 times per day for $\frac{1}{2}$ hour, as well as a HEPA filter in the bedroom at night. The ID residence exhibited higher $F_{\text {in }}(0.31)$, which was likely elevated by the combination of intermittency of filtration with a lower number of filter units and increased natural ventilation from reported opening of windows for multiple hours at night to cool the house. HVAC cooling lowers $F_{\text {in }}$ in part by reducing AER from natural ventilation (Meng et al., 2009; Clark et al., 2010). IAQ of the ID and NV residences were impacted by contributions from cooking and/or cleaning (Wallace, 2006), as suggested by the elevated $C_{s}$ and brief spikes in indoor $\mathrm{PM}_{2.5}$ that are independent of and/or exceeded outdoor $\mathrm{PM}_{2.5}$.

An additional western US residential case study (OR), where occupants also reported closing windows and doors, is presented in Fig. S3. The addition of two HEPA filters and an upgraded HVAC filter during a 2019 wildfire period resulted in $50 \%$ lower infiltration $\left(F_{i n}=0.18\right.$ ) compared to a 2018 wildfire period with standard HVAC filtration $\left(F_{i n}=0.38\right)$. The WA, NV, and OR residences are consistent with prior observations of HEPA filters reducing indoor $\mathrm{PM}_{2.5}$ from wood smoke in homes (Barn et al., 2008; Allen et al., 2011; Wheeler et al., 2014; Ward et al., 2017). One school and two commercial case studies, which all filtered air solely by HVAC and generally exhibited greater $\mathrm{PM}_{2.5}$ infiltration, are presented in Fig. S4. Previously observed dependencies on filtration, ventilation, occupant activity, and room size (Du et al., 2011) potentially contributed to the wide range of $\mathrm{PM}_{2.5}$ infiltration parameters observed in the residential, commercial, and school datasets (Fig. 1).

\subsection{Evaluation of a Low-cost Indoor $\mathrm{PM}_{2.5}$ Filtration Tool}

The efficacy of the MERV-13 FFU in improving IAQ during a smoke event was evaluated with both PAS and submicron particle count information (Fig. 3). During the September 13, 2020 sampling period, the nearest outdoor PAS $(2 \mathrm{~km})$ to the Seattle, WA residence reported sustained elevated outdoor $\mathrm{PM}_{2.5}\left(127 \pm 9 \mu \mathrm{g} \mathrm{m}^{-3}\right)$. Prior to recirculating room air through the FFUs, the PAS measured average $( \pm 1 \sigma) \mathrm{PM}_{2.5}$ of $64 \pm 2 \mu \mathrm{g} \mathrm{m}^{-3}$ in Room $\mathrm{A}(\mathrm{I} / \mathrm{O}=0.50)$ and $40 \pm 2 \mu \mathrm{g} \mathrm{m}^{-3}$ in Room B $(\mathrm{I} / \mathrm{O}=0.31)$. After 90 minutes of FFU recirculation in Room $A, \mathrm{PM}_{2.5}$ reached a consistent $28 \pm 2 \mu \mathrm{g} \mathrm{m}^{-3}(\mathrm{I} / \mathrm{O}=0.22)$, for a $\sim 56 \%$ reduction. In comparison, it took less than 60 minutes of FFU recirculation in Room $B$ to lower average indoor $\mathrm{PM}_{2.5}$ to $0.4 \pm 0.4 \mu \mathrm{g} \mathrm{m}^{-3}$ (I/O =0.003), a $\sim 99 \%$ reduction. Differences in particle removal efficiency by a filter unit between rooms has 

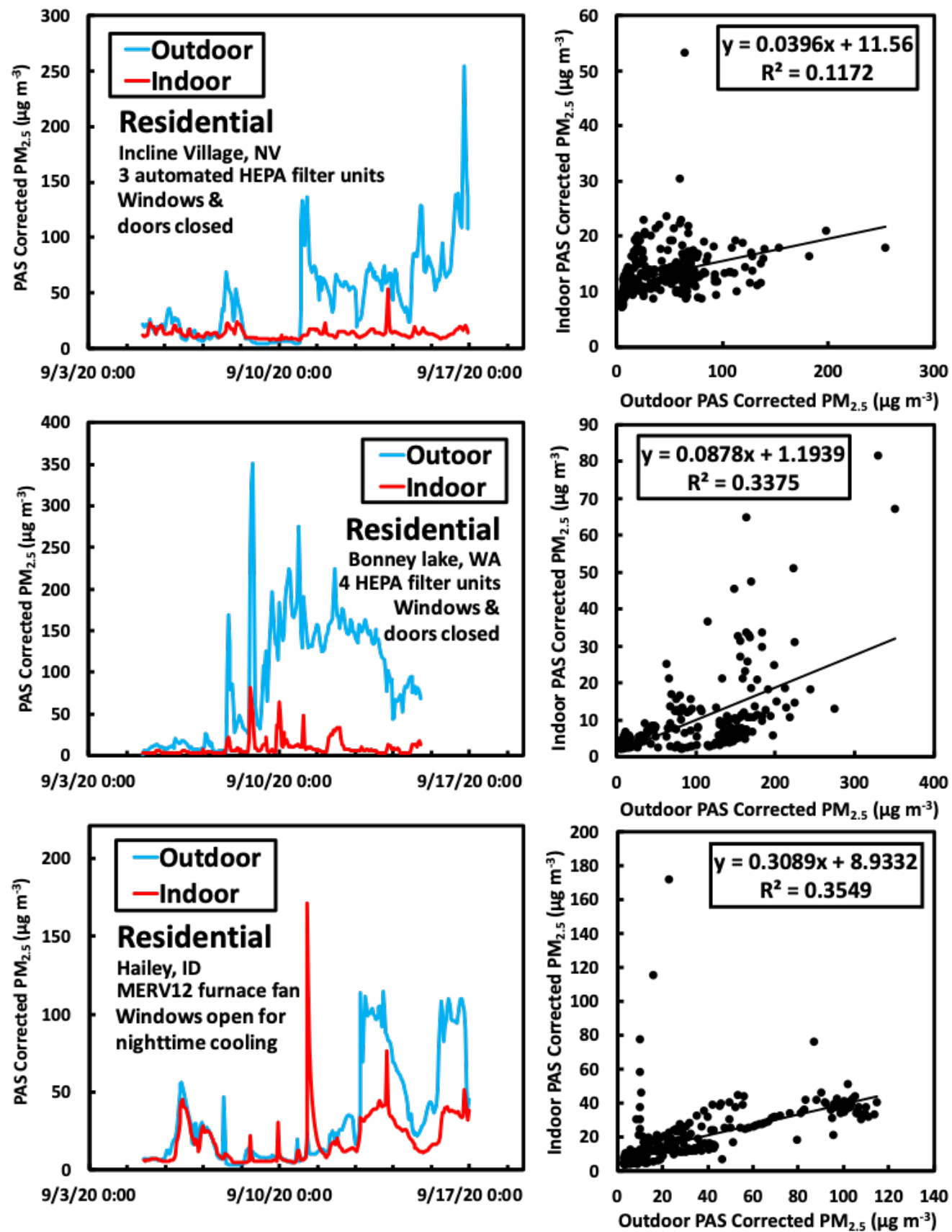

Fig. 2. Outdoor and indoor $\mathrm{PM}_{2.5}$ mass concentrations measured by PurpleAir sensors (PAS) with EPA correction applied for three residential locations during a September 5-15, 2020 period of wildfire smoke. Location name and information on indoor air quality interventions is presented in the time series (left), with corresponding $F_{\text {in }}$ (slope), $C_{S}$ (y-intercept), and correlation coefficients $\left(R^{2}\right)$ presented in correlation plots (right).

previously been shown to be controlled by air exchange and position (Novoselac and Siegel, 2009). Outdoor $\mathrm{PM}_{2.5}$ remained elevated $\left(134 \pm 5 \mu \mathrm{g} \mathrm{m}^{-3}\right)$ during an additional test of the FFU in Room B on September 14, 2020 (Fig. 3). 60 minutes of FFU recirculation reduced indoor $\mathrm{PM}_{2.5}$ from $73 \pm 1 \mu \mathrm{g} \mathrm{m}^{-3}(\mathrm{I} / \mathrm{O}=0.47)$ to $6.2 \pm 0.6 \mu \mathrm{g} \mathrm{m}^{-3}(\mathrm{I} / \mathrm{O}=0.04)$, a $\sim 91 \%$ reduction. Corrected particle number concentrations measured by the Grainger particle counter demonstrated the FFU filtered 0.3-1.0 $\mu \mathrm{m}$ particles at a comparable efficiency ( $>90 \%$ ) as $\mathrm{PM}_{2.5}$. Substantial reductions in $\mathrm{PM}_{2.5}$ and $0.3-1.0 \mu \mathrm{m}$ particles after FFU recirculation further demonstrate the utility of lowcost methods for improving IAQ during smoke events (Tham et al., 2018, 2020). 


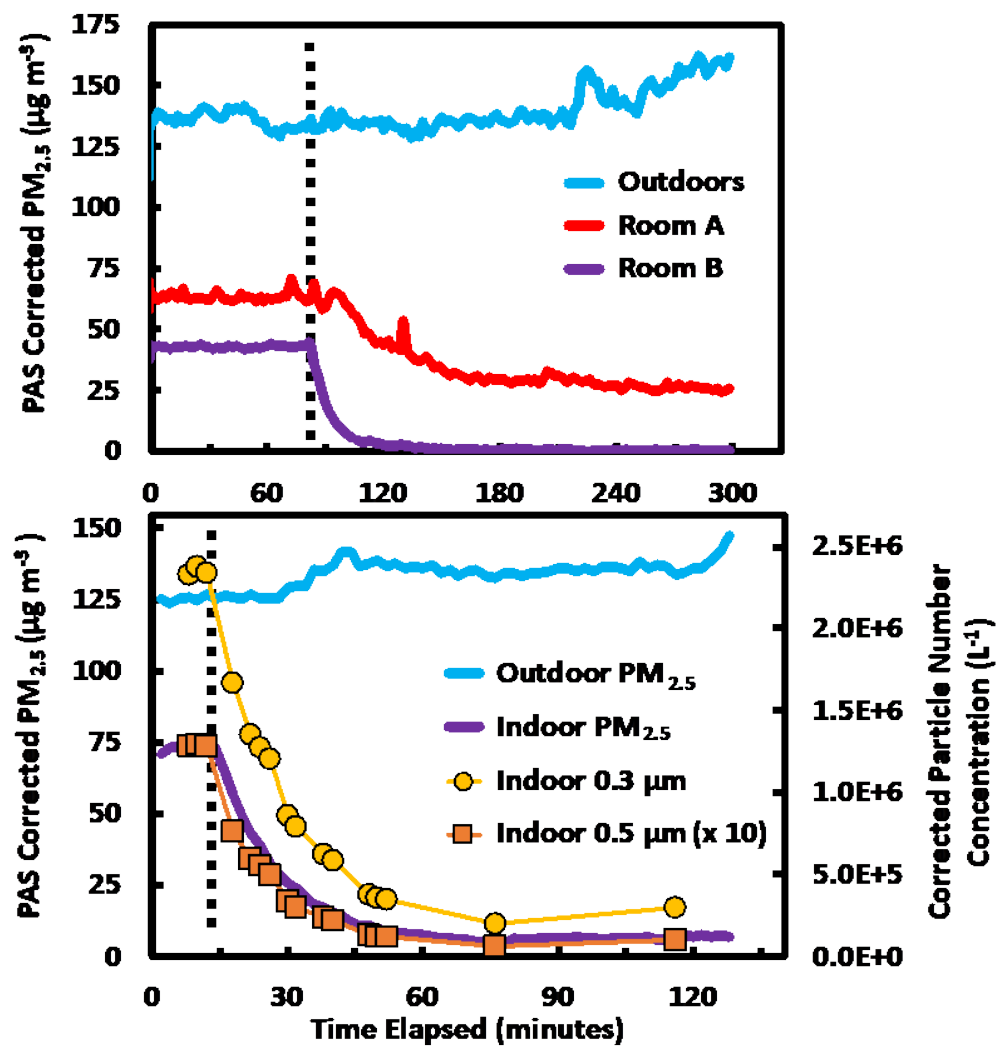

Fig. 3. (Top) $P M_{2.5}$ mass concentrations measured on September 13, 2020, by PurpleAir sensors (PAS) before and after, as denoted by dashed line, recirculating indoor air through the MERV-13 fan filter unit in Room A $\left(200 \mathrm{~m}^{3}\right)$ and Room B $\left(50 \mathrm{~m}^{3}\right)$ of a Seattle, WA, home impacted by wildfire smoke. (Bottom) PM2.5 mass concentrations measured on September 14, 2020, by a PAS, as well as 0.3 and $0.5 \mu \mathrm{m}$ size bin corrected particle number concentrations measured by the Grainger particle counter, before and after, as denoted by dashed line, recirculating indoor air through the MERV-13 fan filter unit in Room B.

The CADR of the MERV-13 FFU was estimated as the product of average air flow $\left(1130 \mathrm{~m}^{3} \mathrm{~h}^{-1}\right)$ and 0.3-1.0 $\mu \mathrm{m}$ MERV-13 filtration efficiency (50\%) to be $560 \mathrm{~m}^{3} \mathrm{~h}^{-1}$. The operating cost effectiveness, defined as the CADR per electric power consumption of the fan (maximum 100 watts), was estimated to be 5.6 CADR/watt. However, CADR and CADR/watt are likely overestimated here because this method does not account for imperfect mixing and recirculation reducing experimental filtration efficiency. The CADR of commercial HEPA filter units ranges from $200-700 \mathrm{~m}^{3} \mathrm{~h}^{-1}$, with power consumption ranging from 30-200 watts and cost effectiveness ranging from 1-7.2 CADR/watt (Waring et al., 2008; Sultan et al., 2011; Noh and Yook, 2016; Shi and Li, 2019). The MERV-13 FFU described here is in the middle of the range of CADR and CADR/watt for commercial HEPA units, but at much lower initial cost. Future work is needed to determine the MERV-13 FFU effective air cleaning ratio (EACR), which is the ratio of the experimental CADR to the theoretical CADR (Noh and Oh, 2015), as well as the filtration efficiency of ultrafine particles (Laing et al., 2016) and gas-phase components of wildfire smoke (Kirk et al., 2018; Messier et al., 2019).

Calculated $Q_{\text {inf }}$ from Eq. (3) (Shi and Li, 2019), which were higher for Room A (181 $\mathrm{m}^{3} \mathrm{~h}^{-1}$ ) than Room $B\left(1.76 \mathrm{~m}^{3} \mathrm{~h}^{-1}\right)$, were divided by room size to estimate AER. Residential AER is a predictor of $\mathrm{PM}_{2.5}$ infiltration and exposure (Meng et al., 2009). The estimated AER of the larger and more externally connected Room A $\left(0.91 \mathrm{~h}^{-1}\right)$ was a factor of 25 higher than the smaller and less externally connected Room B $\left(0.035 \mathrm{~h}^{-1}\right)$, with both values falling within the range of prior residential observations (Yamamoto et al., 2010). The reduced performance of the FFU in the high AER Room A compared to the low AER Room B (Fig. 3) highlights the impact of ventilation on filter performance. The lower $F_{\text {in }}$ observed in the prior WA, NV, and OR residential case studies (Figs. 2 and S3) may also be explained by low AER, as well as high CADR from multiple filter units. 
Buildings and rooms with greater AER may thus require multiple filter units to increase CADR and maximize potential reductions in $\mathrm{PM}_{2.5}$ exposure during smoke events.

\section{CONCLUSIONS}

Indoor and outdoor $\mathrm{PM}_{2.5}$ measurements by PAS were used to evaluate $\mathrm{PM}_{2.5}$ infiltration in western US residential, commercial, and school buildings during a period of wildfire smoke. Infiltration of ambient smoke was the predominant source of indoor $\mathrm{PM}_{2.5}$, and contributions from indoor sources were minor (Fig. 1). Building type median $F_{i n}, \mathrm{l} / \mathrm{O}$, and $\mathrm{R}^{2}$ calculated from PAS indoor and outdoor $\mathrm{PM}_{2.5}$ concentrations corresponded to ASHRAE-recommended ventilation rates (ASHRAE, 2019b, 2019a), with infiltration reduced in low air exchange residential buildings and elevated in high air exchange commercial and school buildings.

The use of multiple filter units in residences, in addition to closing all windows and doors, was associated with substantially lower residential $F_{\text {in }}$ (Figs. 2 and S3). The low-cost filtration method presented here, which was shown to effectively remove $\mathrm{PM}_{2.5}$ (Fig. 3), provides a cost-effective alternative to commercial filter units for improving IAQ during wildfire smoke periods. One FFU was most effective in reducing $\mathrm{I} / \mathrm{O}$ in a room with lower estimated air exchange. In a larger room or with larger air exchange, additional FFUs could be installed. Widespread dissemination of information and recommendations of filtration interventions, such as the low-cost method presented here, has the potential to substantially reduce indoor $\mathrm{PM}_{2.5}$ exposure during the western US wildfire season.

\section{SUPPLEMENTARY MATERIAL}

Supplementary data associated with this article can be found in the online version at https://doi.org/10.4209/aaqr.210046

\section{REFERENCES}

Abatzoglou, J.T., Williams, A.P. (2016). Impact of anthropogenic climate change on wildfire across western US forests. Proc. Natl. Acad. Sci. U.S.A. 113, 11770-11775. https://doi.org/10.1073/p nas.1607171113

Allen, R.W., Carlsten, C., Karlen, B., Leckie, S., Eeden, S. van, Vedal, S., Wong, I., Brauer, M. (2011). An air filter intervention study of endothelial function among healthy adults in a woodsmokeimpacted community. Am. J. Respir. Crit. Care Med. 183, 1222-1230. https://doi.org/10.1164/ rccm.201010-15720C

Allen, R.W., Barn, P. (2020). Individual- and household-level interventions to reduce air pollution exposures and health risks: A review of the recent literature. Curr. Environ. Health Reports 7, 424-440. https://doi.org/10.1007/s40572-020-00296-z

American Society of Heating and Air-Conditioning Engineers (ASHRAE) (2019a). ANSI/ASHRAE Standard 62.2-2019 Ventilation and Acceptable Indoor Air Quality in Residential Buildings.

American Society of Heating and Air-Conditioning Engineers (ASHRAE) (2019b). ANSI/ASHRAE Standard 62.1-2019 Ventilation for Acceptable Indoor Air Quality.

Ardon-Dryer, K., Dryer, Y., Williams, J.N., Moghimi, N. (2020). Measurements of PM2.5 with PurpleAir under atmospheric conditions. Atmos. Meas. Tech. 13, 5441-5458. https://doi.org/ 10.5194/amt-13-5441-2020

Barkjohn, K.K., Gantt, B., Clements, A.L. (2020). Development and application of a United States wide correction for $\mathrm{PM}_{2.5}$ data collected with the PurpleAir sensor. Atmos. Meas. Tech. Discuss. https://doi.org/10.5194/amt-2020-413

Barkjohn, K.K., Norris, C., Cui, X., Fang, L., Zheng, T., Schauer, J.J., Li, Z., Zhang, Y., Black, M., Zhang, J., Bergin, M.H. (2021). Real-time measurements of $\mathrm{PM}_{2.5}$ and ozone to assess the effectiveness of residential indoor air filtration in Shanghai homes. Indoor Air 31, 74-87. https://doi.org/10.1 111/ina.12716

Barn, P., Larson, T., Noullett, M., Kennedy, S., Copes, R., Brauer, M. (2008). Infiltration of forest 
fire and residential wood smoke: An evaluation of air cleaner effectiveness. J. Exposure Sci. Environ. Epidemiol. 18, 503-511. https://doi.org/10.1038/sj.jes.7500640

Bucur, E., Danet, A. (2019). Indoor/outdoor correlations regarding indoor air pollution with particulate matter. Environ. Eng. Manage. J. 18, 425-432. https://doi.org/10.30638/eemj.201 9.040

Cascio, W.E. (2018). Wildland fire smoke and human health. Sci. Total Environ. 624, 586-595. https://doi.org/10.1016/j.scitotenv.2017.12.086

Clark, N.A., Allen, R.W., Hystad, P., Wallace, L., Dell, S.D., Foty, R., Dabek-Zlotorzynska, E., Evans, G., Wheeler, A.J. (2010). Exploring variation and predictors of residential fine particulate matter infiltration. Int. J. Environ. Res. Public Health 7, 3211-3224. https://doi.org/10.3390/ije rph7083211

Davison, G., Barkjohn, K.K., Hagler, G.S.W., Holder, A.L., Coefield, S., Noonan, C., Hassett-Sipple, B. (2021). Creating clean air spaces during wildland fire smoke episodes: Web Summit summary. Front. Public Health 9, 508971. https://doi.org/10.3389/fpubh.2021.508971

Delp, W.W., Singer, B.C. (2020). Wildfire smoke adjustment factors for low-cost and professional $\mathrm{PM}_{2.5}$ monitors with optical sensors. Sensors 20, 3683. https://doi.org/10.3390/s20133683

Deng, G., Li, Z., Wang, Zhichao, Gao, J., Xu, Z., Li, J., Wang, Z. (2015). Indoor/outdoor relationship of $\mathrm{PM}_{2.5}$ concentration in typical buildings with and without air cleaning in Beijing. Indoor Built Environ. 26, 60-68. https://doi.org/10.1177/1420326X15604349

Du, L., Batterman, S., Parker, E., Godwin, C., Chin, J.Y., O’Toole, A., Robins, T., Brakefield-Caldwell, W., Lewis, T. (2011). Particle concentrations and effectiveness of free-standing air filters in bedrooms of children with asthma in Detroit, Michigan. Build. Environ. 46, 2303-2313. https://doi.org/10.1016/j.buildenv.2011.05.012

Fisk, W.J., Chan, W.R. (2017). Health benefits and costs of filtration interventions that reduce indoor exposure to $\mathrm{PM}_{2.5}$ during wildfires. Indoor Air 27, 191-204. https://doi.org/10.1111/in a.12285

Grimm, H., Eatough, D.J. (2009). Aerosol measurement: The use of optical light scattering for the determination of particulate size distribution, and particulate mass, including the semi-volatile fraction. J. Air Waste Manage. Assoc. 59, 101-107. https://doi.org/10.3155/1047-3289.59.1.101

Holder, A.L., Mebust, A.K., Maghran, L.A., McGown, M.R., Stewart, K.E., Vallano, D.M., Elleman, R.A., Baker, K.R. (2020). Field evaluation of low-cost particulate matter sensors for measuring wildfire smoke. Sensors 20, 4796. https://doi.org/10.3390/s20174796

Hooper, L.G., Kaufman, J.D. (2018). Ambient air pollution and clinical implications for susceptible populations. Ann. Am. Thorac. Soc. 15, S64-S68. https://doi.org/10.1513/AnnalsATS.201707$574 \mathrm{MG}$

Jaffe, D.A., O’Neill, S.M., Larkin, N.K., Holder, A.L., Peterson, D.L., Halofsky, J.E., Rappold, A.G. (2020). Wildfire and prescribed burning impacts on air quality in the United States. J. Air Waste Manage. Assoc. 70, 583-615. https://doi.org/10.1080/10962247.2020.1749731

Kirk, W.M., Fuchs, M., Huangfu, Y., Lima, N., O’Keeffe, P., Lin, B., Jobson, T., Pressley, S., Walden, V., Cook, D., Lamb, B.K. (2018). Indoor air quality and wildfire smoke impacts in the Pacific Northwest. Sci. Technol. Built Environ. 24, 149-159. https://doi.org/10.1080/23744731.2017.1393256

Laing, J.R., Jaffe, D.A., Hee, J.R. (2016). Physical and optical properties of aged biomass burning aerosol from wildfires in Siberia and the Western USA at the Mt. Bachelor Observatory. Atmos. Chem. Phys. 16, 15185-15197. https://doi.org/10.5194/acp-16-15185-2016

Laing, J.R., Jaffe, D.A. (2019). Wildfires are causing extreme PM concentrations in the western United States. EM: Air and Waste Management Associations's Magazine for Environmental Managers.

Laumbach, R.J. (2019). Clearing the air on personal interventions to reduce exposure to wildfire smoke. Ann. Am. Thorac. Soc. 16, 815-818. https://doi.org/10.1513/AnnalsATS.201812-894PS

Li, J., Mattewal, S.K., Patel, S., Biswas, P. (2020). Evaluation of nine low-cost-sensor-based particulate matter monitors. Aerosol Air Qual. Res. 20, 254-270. https://doi.org/10.4209/aaqr. 2018.12.0485

Meng, Q.Y., Spector, D., Colome, S., Turpin, B. (2009). Determinants of indoor and personal exposure to $\mathrm{PM}_{2.5}$ of indoor and outdoor origin during the RIOPA study. Atmos. Environ. 43, 5750-5758. https://doi.org/10.1016/j.atmosenv.2009.07.06

Messier, K.P., Tidwell, L.G., Ghetu, C.C., Rohlman, D., Scott, R.P., Bramer, L.M., Dixon, H.M., 
Waters, K.M., Anderson, K.A. (2019). Indoor versus outdoor air quality during wildfires. Environ. Sci. Technol. Lett. 6, 696-701. https://doi.org/10.1021/acs.estlett.9b00599

National Interagency Fire Center (2020). https://www.nifc.gov/

Noh, K.C., Oh, M.D. (2015). Variation of clean air delivery rate and effective air cleaning ratio of room air cleaning devices. Build. Environ. 84, 44-49. https://doi.org/10.1016/j.buildenv.2014.10.031

Noh, K.C., Yook, S.J. (2016). Evaluation of clean air delivery rates and operating cost effectiveness for room air cleaner and ventilation system in a small lecture room. Energy Build. 119, 111118. https://doi.org/10.1016/j.enbuild.2016.03.027

Novoselac, A., Siegel, J.A. (2009). Impact of placement of portable air cleaning devices in multizone residential environments. Build. Environ. 44, 2348-2356. https://doi.org/10.1016/j. buildenv.2009.03.023

Rappold, A.G., Reyes, J., Pouliot, G., Cascio, W.E., Diaz-Sanchez, D. (2017). Community vulnerability to health impacts of wildland fire smoke exposure. Environ. Sci. Technol. 51, 6674-6682. https://doi.org/10.1021/acs.est.6b06200

Reid, C.E., Brauer, M., Johnston, F.H., Jerrett, M., Balmes, J.R., Elliott, C.T. (2016). Critical review of health impacts of wildfire smoke exposure. Environ. Health Perspect. 124, 1334-1343. https://doi.org/10.1289/ehp.1409277

Reiman, J.M., Das, B., Sindberg, G.M., Urban, M.D., Hammerlund, M.E.M., Lee, H.B., Spring, K.M., Lyman-Gingerich, J., Generous, A.R., Koep, T.H., Ewing, K., Lilja, P., Enders, F.T., Ekker, S.C., Huskins, W.C., Fadel, H.J., Pierret, C. (2018). Humidity as a non-pharmaceutical intervention for influenza A. PLoS One 13, e0204337. https://doi.org/10.1371/journal.pone.0204337

Reisen, F., Powell, J.C., Dennekamp, M., Johnston, F.H., Wheeler, A.J. (2019). Is remaining indoors an effective way of reducing exposure to fine particulate matter during biomass burning events? J. Air Waste Manage. Assoc. 69, 611-622. https://doi.org/10.1080/10962247.2019.15 67623

Schoen, L.J. (2020). EQ Applications: Guidance for Building Operations during the COVID-19 Pandemic. ASHRAE J. 62, 3.

Shi, Y., Li, X. (2019). A convenient method to assess air infiltration rate using particle mass balance principle. E3S Web Conf. 111, 06039. https://doi.org/10.1051/e3sconf/201911106039

Shrestha, P.M., Humphrey, J.L., Carlton, E.J., Adgate, J.L., Barton, K.E., Root, E.D., Miller, S.L. (2019). Impact of outdoor air pollution on indoor air quality in low-income homes during wildfire seasons. Int. J. Environ. Res. Public Health 16, 3535. https://doi.org/10.3390/ijerph16193535

Sultan, Z.M., Nilsson, G.J., Magee, R.J. (2011). Removal of ultrafine particles in indoor air: Performance of various portable air cleaner technologies. HVAC\&R Res. 17, 513-525. https://doi.org/10.1080/10789669.2011.579219

Tham, K.W., Parshetti, G.K., Anand, P., Cheong, D.K.W., Sekhar, C. (2020). Performance characteristics of a fan filter unit (FFU) in mitigating particulate matter levels in a naturally ventilated classroom during haze conditions. Indoor Air 31: 795-806. https://doi.org/10.1111/ ina.12771

Tham, K.W., Parshetti, G.K., Balasubramanian, R., Sekhar, C., Cheong, D.K.W. (2018). Mitigating particulate matter exposure in naturally ventilated buildings during haze episodes. Build. Environ. 128, 96-106. https://doi.org/10.1016/j.buildenv.2017.11.036

Thatcher, T.L., Layton, D.W. (1995). Deposition, resuspension, and penetration of particles within a residence. Atmos. Environ. 29, 1487-1497. https://doi.org/10.1016/1352-2310(95)00016-R

Thurston, G.D., Kipen, H., Annesi-Maesano, I., Balmes, J., Brook, R.D., Cromar, K., De Matteis, S., Forastiere, F., Forsberg, B., Frampton, M.W., Grigg, J., Heederik, D., Kelly, F.J., Kuenzli, N., Laumbach, R., Peters, A., Rajagopalan, S.T., Rich, D., Ritz, B., ..., Brunekreef, B. (2017). A joint ERS/ATS policy statement: What constitutes an adverse health effect of air pollution? An analytical framework. Eur. Respir. J. 49, 1600419. https://doi.org/10.1183/13993003.004192016

Wallace, L. (1996). Indoor particles: A review. J. Air Waste Manage. Assoc. 46, 98-126. https://doi.org/10.1080/10473289.1996.10467451

Wallace, L. (2006). Indoor sources of ultrafine and accumulation mode particles: Size distributions, size-resolved concentrations, and source strengths. Aerosol Sci. Technol. 40, 348-360. https://doi.org/10.1080/02786820600612250

Ward, T.J., Semmens, E.O., Weiler, E., Harrar, S., Noonan, C.W. (2017). Efficacy of interventions 
targeting household air pollution from residential wood stoves. J. Exposure Sci. Environ. Epidemiol. 27, 64-71. https://doi.org/10.1038/jes.2015.73

Waring, M.S., Siegel, J.A., Corsi, R.L. (2008). Ultrafine particle removal and generation by portable air cleaners. Atmos. Environ. 42, 5003-5014. https://doi.org/10.1016/j.atmosenv.2008.02.011

Wheeler, A.J., Gibson, M.D., MacNeill, M., Ward, T.J., Wallace, L.A., Kuchta, J., Seaboyer, M., Dabek-Zlotorzynska, E., Guernsey, J.R., Stieb, D.M. (2014). Impacts of air cleaners on indoor air quality in residences impacted by wood smoke. Environ. Sci. Technol. 48, 12157-12163. https://doi.org/10.1021/es503144h

Westerling, A.L. (2016). Increasing western US forest wildfire activity: Sensitivity to changes in the timing of spring. Philos. Trans. R. Soc. London, Ser. B 371, 20150178. https://doi.org/10.10 98/rstb.2015.0178

Yamamoto, N., Shendell, D.G., Winer, A.M., Zhang, J. (2010). Residential air exchange rates in three major US metropolitan areas: Results from the Relationship Among Indoor, Outdoor, and Personal Air Study 1999-2001. Indoor Air 20, 85-90. https://doi.org/10.1111/j.1600-0668.200 9.00622.x 